\title{
Electronic Patient Records: Moving from Islands and Bridges towards Electronic Health Records for Continuity of Care
}

\author{
Petra Knaup', Oliver Bott', Christian Kohl', Christian Lovis ${ }^{3}$, Sebastian Garde ${ }^{4}$ \\ 'Department of Medical Informatics, University of Heidelberg, Germany \\ 2Institute for Medical Informatics, Technical University of Braunschweig, Germany \\ ${ }^{3}$ Service of Medical Informatics, University Hospital of Geneva, Geneva, Switzerland \\ ${ }^{4}$ Health Informatics Research Group, Central Queensland University; Austin Health, Melbourne, Vic, Australia
}

\begin{abstract}
Summary
Objectives: Electronic patient record (EPR) systems are increasingly used and have matured sufficiently so as to contribute to high quality care and efficient patient management. Our objective is to summarize current trends and major achievements in the field of EPR in the last year and to discuss their future prospects.

Results: Integrating health data from a variety of sources in a comprehensive EPR is a major prerequisite for e-health and eresearch. Current research continues to elaborate architectures, technologies and security concepts. To achieve semantic interoperability standards are developed on different levels, including basic data types, messages, services, architectures, terminologies, ontologies, scope and presentation of EPR content. Standards development organisations have started to harmonize their work to arrive at a consensus standard for EPR systems. Integrating the health care enterprise as a whole will optimize efficient use of resources, logistics and scheduling.

Conclusions: The past few years have seen a myriad of developments of EPR systems. However, it i s still a long way, until EPR systems can flexibly fulfill all user requirements and an EHR will become broadly accepted. Semantic interoperability will be a key to successful EPR use, especially to avoid double data entries and to better integrate data recording within local workflows. The patient will become an empowered partner, not only by giving him access to his health data. All this will result in enormous quantities of data. Thus, time has come to determine how relevant data can be presented to the stakeholders adequately.

\section{Keywords}

Computerized patient record systems, electronic health record, standards, interoperability, medical informatics

Geissbuhler A, Haux R, KulikowskiC, editors. IMIA Yearbook of Medical Informatics2007. Methods InfMed 2007; 46Supp 1:34-46
\end{abstract}

\section{Introduction}

\section{Subject and Relevance}

Modern health care is increasingly influenced by e-health, although there is still no consensus on a comprehensive definition of the term [1]. The use of established and emerging interactive technologies like the Internet, voice response systems, or mobile computing [2] is growing. The expectation is that ehealth will contribute to high quality information, data exchange and patient care. This can become reality, if health information technology is widely adopted and health information is exchanged electronically between two entities, when appropriate (http://ehealth.ky.gov/). But innovative applications for example in telehealth [3] or health grid technologies [4], are only efficient if there are comprehensive electronic patient records to collect, store and analyze health data and to present relevant data at the point of care or for policy makers.

The benefits of documenting the health status of patients and citizens has been known for centuries [5]. Patient records are nowadays the most important media for communication, research and monitoring in health care. Mobility, increased specialization, new media for data capture and storage and secondary data analysis require electronic representation of health data. Communication media like paper-based discharge letters are no longer sufficient, especially in times of highly specialized cooperative care, because they are often not in time or not available in time or not complete [6,7]. Changes of media, processes and attitudes are necessary to move from historic paper-based representation over islands of EPRs system and bridges for communication to continuous high quality patient care supported by comprehensive electronic health records.

\section{Problems and Motivation}

Although EPR systems are increasingly used, there still remain barriers to their adoption [8-12]. There is a huge gap between the availability of innovative technologies and their application in daily health care. Reasons for this include the inherent complexity of the field, costs, as well as ethical and legal requirements.

Due to the sensitivity of health data, concepts for data privacy and security have to be established before applying new technologies like radio-frequency tags (RFID) e.g. for evaluating endotracheal tube position [13] or blood information management [14]. Architectures for hospital information systems should be open, so that new technologies can be integrated as soon as they are available and secure. Hospital information systems are heterogeneous 
and complex. Interoperability of application systems is still not easy to achieve, but is expected to be valuable [15]. This leads to the development of architecture standards for EPR systems.

Working architecture standards still do not guarantee semantic interoperability, which is a major prerequisite for usability. Efforts for terminological standards or clinical archetypes seek to ensure that different application systems and different users share understanding and knowledge. Only when semantic interoperability is given, an EPR can be truly integrated into the HIS as an integral part of workflow, billing and logistic management. These are major requirements for acceptance of EPR by health professionals and therefore for usability in clinical routine. All the above mentioned problems are still not solved completely for institution-wide patient records. Another level of complexity is imposed with the institution-independent electronic health record (EHR). E-health ignores institutional boundaries and tries to share patient data among institutions, to make patient data ubiquitously available worldwide for health care as well as for clinical research, epidemiological research, bio-surveillance and population health reporting. Establishing EHRs as a patientcentered approach will involve the patient more deeply in the care process as he becomes responsible for keeping and recording his own health data and for making the right data available to the right persons at the right point in time. Access to information is seen as one major element of patient empowerment [16]. The need for truly empowered patients is not restricted to just today's example problems like diabetes care [17] or in-vitro fertilization [18].

\section{Objectives}

The objective of our paper is to summarize current trends and major achieve- ments in the field of electronic patient records in the last year and to discuss its prospects, with a major focus on

- multiple use of data for e-health and e-research

- architectures and technologies for patient record systems

- standards for semantic interoperability, and

- integration of EPR systems into the hospital information system.

\section{Background and State of the Art}

We use the term institution-wide patient record as defined in ([19], p. 176): "The patient record comprises all data and documents generated or received during the care of a patient at a health care institution" and an electronic patient record (EPR) is "a complete or partial patient record stored on an electronic storage medium, or document carrier." We use electronic patient record $(E P R)$ as the generic concept for all kinds of records including institutionwide electronic records, shared patient records and even the electronic health record. We use the term electronic health record for the institution independent, patient-centered, long-term patient record, as defined by ISO "The Integrated Care Electronic Health Record is defined as a repository of information regarding the health of a subject of care in computer processable form, stored and transmitted securely, and accessible by multiple authorized users. It has a commonly agreed logical information model which is independent of EHR systems. Its primary purpose is the support of continuing, efficient and quality integrated health care and it contains information which is retrospective, concurrent and prospective." (ISO/DTR 20514: International Organization for Standardization Draft Technical Report on EHR Defi- nition, Scope and Context). We regard a personal health record as the patient's personal collection of health data and documents. This should ideally be fully interoperable with the EPR [20].

As described in the last IMIA Yearbook, EPR-systems are now mature, so that they can contribute to high quality patient care and efficient patient management [21-23]. As the survey by Jaspers et al. [24]concludes, the EPR “... is playing a growing part in medical informatics research and evaluation studies, but the goal of establishing a comprehensive lifelong EHR is still a long way off. In moving forward to EHRs, convergence of EHR standards seems required to realize true interoperability of health care applications." Thus, our focus in this years' survey is on interoperability and the variety of standards.

\section{Recent Research and Future Developments for Electronic Patient Records}

\subsection{EPR as a Core Component of e- Health and e-Research}

\section{State of the Art}

Although EPR systems are increasingly used [25], patient data is often spread over different application systems. Wards and functional areas store patient data in various, often unintegrated application systems. Much effort is needed to integrate all data from different data sources into an EPR. Unambiguous patient identification is an often an underestimated difficulty, for instance a 'master patient ID' may be used [26]. A universal way to identify patients is still missing.

Although getting a unified institutionwide EPR is already a challenge, this leads only to limited results when we 
Knaup et al.

consider patient mobility, community networking or clinical research. It is a matter of medical informatics research to enable trans-institutional EPR access or exchange [27]. The claim for methods and tools that support multi-institutional collaboration is not new [28]. But up to now there are only isolated examples reporting on sharing data among EPR systems in different institutions [29, 30]. Barriers to trans-institutional interoperability include concerns with data privacy, and patient safety as well as heterogeneity of application systems and terminologies.

Data exchange for multicenter clinical trials also has to extend beyond institutional boarders. A vrey large number of clinical trials is still paper-based, although web-based technologies can be used for randomization, remote data entry (RDE), patient enrolment [31], follow-up, information distribution, study monitoring, and overall study management [32]. But even if RDE is available at the clinical site, it is usually not possible to integrate the data from the local EPR in the RDE-system. This means that each value for the trial has to be entered manually into the remote interface. Multiple recording of the same data cannot be avoided, which is time-consuming [33] and error-prone. The cost of validated, randomized clinical trials is becoming unmanageable and there is a growing demand for using EPR data for secondary analyses [34].

\section{Current Developments in the Last Year (2006 up to the present)}

Sharing patient data among different institutions goes beyond technical issues to also encompass security and privacy concerns. When data from EPRs is collected for clinical trials, anonymization is necessary [35-38] or patients have to be asked for consent. In the case of clinical narratives a de-identification of protected health information is necessary. Simple automated techniques did not perform as well as human reviewers [39].

Instead of interoperability of a variety of EPR-systems an EHR stored in a central database could be used by different persons and institutions to enter and share information about the patient independent from the patient's current location. A lifetime EHR is not restricted to clinical data but contains also wellness data (e.g. a personal physical fitness program) and information recorded by the patient himself. Shabo suggested in [40] that so called 'independent health record banks' should function as new players in health care, which maintain lifetime EHRs comparable to how banks hold monetary funds in trust. An issue that will need to be addressed is whether such 'independent health record banks' can in the long run be responsible for long term record keeping instead of the health care institutions. As alternative approach the provider-centric model, the consumercentric model and national repositories for EHR are analyzed in[41]. For using health data for multiple purposes like patient care and clinical research independent health record banks involve the greatest potential, because of their huge amount of clinical data in standardized formats, they could serve as a source for automated data collection in clinical trials. A special service between the gateway to the EHR-bank and the underlying data base could automatically perform an anonymization of the patient data. (http://www.egms.de/en/ meetings/gmds2006/06gmds238.shtml) New data sources from genomics and proteomics pose new challenges to the medical informatics community. To identify the correlation between genotype and phenotype integrated clinical data and research data have to be analysed in sufficient numbers. New data structures are necessary for (re)presenting genotype information in EPRs. "We do not only need the results, but also the raw data, because the data has to be reanalysed frequently as new insight could lead to different results" [42]. Sax introduces several ways of integrating genomic data in EHR as the main source of phenotypic data. He claims that more standardization of terminologies and ontologies is necessary.

Initiatives like $\mathrm{caBIG}^{\text {tm }}$ (cancer Biomedical Informatics Grid) [43, 44] already work in this direction and try to integrate different data sources to support clinical trials and research. caBIG ${ }^{\text {tm }}$ aims to facilitate coordination of research and data exchange among multiple institutions to "... leverage their combined strengths and expertise in cancer research" by developing a "... federation of interoperable research information systems" [45]. Different tools try to bring together genomics, proteomics and clinical data. These tools have to integrate different vocabularies to describe findings and different standards for reporting research (http:// cabig.cancer.gov/resources/video.asp, last accessed June 1, 2007). To cope with this, the National Cancer Institute in the USA has developed the cancer Common Ontologic Representation Environment (caCORE). A special caCORE software development kit was designed to "... lower the barrier to implementing systems that are syntactically and semantically interoperable ..." [46]. A four layer approach is used to achieve that interoperability. "One layer is concerned with the syntactic component of interoperability, while the remaining three layers are concerned with the semantic part of interoperability. These layers are (1) interface integration, (2) information models, (3) semantic metadata, and (4) controlled vocabularies and ontologies" [47]. Services which 
were created using the caCORE SDK and fulfill certain caBIGtm compatibility guidelines can be connected to the caGrid, the core architecture of $\mathrm{caBIG}^{\text {tm }} \mathrm{s}$ interoperability efforts - "... a standardized framework for the advertising, discovery, and invocation of data and analytical resources" [45]. caGrid is based on a model-driven, service oriented architecture. In December 2006 Version 1.0 of caGrid has been released.

\section{Prospects}

Home monitoring is an attractive topic for many stakeholders. It has the potential of patient empowerment, influencing patients' attitudes and behaviors and increasing desirable medical outcomes [48]. As a substitute for hospitalization it has yet to be proved as a really efficient way to decrease inpatient stays and to reduce costs. In their seventh framework program, the European Union fosters remote monitoring of patients within their preferred environments, including homes. Since home monitoring includes not only monitoring patient status at a distance [49] but also automated electronic transmission of data on the patient's health status to a health care institution a significant amount of data is produced. Concepts have to be developed to integrate this data into patient records or health records respectively. Intelligent algorithms are necessary to process and present this data fulfilling the information needs of health care professionals [50] and avoiding information overload [51]. Together with technological advances for wireless communication and miniaturized devices, e.g. for wearable computing, inobtrusive and continuous monitoring seems possible [49].

Other emerging technologies like ehealth-cards, should also be combined with EHRs. The card can carry emergency information, e-prescriptions and can serve as identification. It can become the access key to a patient's comprehensive EHR stored remotely or containing the complete health data. The (planned) introduction of such e-health cards in numerous European countries shows that it is not trivial to establish a countrywide telematics infrastructure for health-cards. It is considerably more difficult to provide a corresponding EHR-system [6, 52, 53], although a variety of standards is available.

Given a working EHR-system new problems have to be solved. The EHR - especially for older people with multiple diseases - will contain a huge amount of data. It will be necessary to filter the information which is essential for a particular health professional faced with a specific health care situation and to present it in an appropriate way. Besides presentation strategies, special and new data mining technologies for text and audio-visual content will also need to be developed; such as automatic categorization of medical images for content-based retrieval [54] or graphical navigation of EHRs using Google Earth [55].

\subsection{EPR-Technologies and Architectures}

\section{State of the Art}

Implementing EPR systems requires deciding on the technologies and architectures to be used. This needs to consider the following, partly interdependent aspects: data safety and security, integration and interoperability, record storage, and implementation architecture. Data safety and security are of the uppermost importance for storing and communicating patient related health data [56]. This is true for institutionwide EPR systems but all the more for EHR systems [57]. Traditional concepts like login names and passwords for ac- cess and DBMS systems with unencrypted data storage are still state of the art in institution-wide health information systems (iHIS, e.g. hospital information system). Current approaches to implementing EHR systems require sophisticated security architectures which would benefit from international standards. Strong authentication, encryption and digital signatures based on public key infrastructures including role and policy definitions are current approaches [58]. Smart cards for patients and health care professionals are widely used to support secure communication and co-operation in a shared care environment [59]. Integrating patients in managing access to their EHR data can be realized by an e-consent based approach [60].

Integration and interoperability reflect the basic requirement that patient data stored in an EPR system can be exchanged with other application systems not only on a technical but also on a semantically sound basis [61]. This is closely related to HIS standards for health data exchange like HL 7 version 3 [62] and the related clinical document standard CDA [63]. Also, the CEN ENV 13606 "Health Informatics - EHCR Communication" and its revision that are based on the openEHR approach [64] is directed towards standardizing communication of EHR components. Architectures and implementations of EHR systems are reflecting this through implementing interfaces based on XML [65], HL7 Version 3 [66], CDA [67-69], or openEHR [70]. Semantic interoperability goes beyond technically realizing data exchange and uses coding schemes like CDA templates or openEHR archetypes and ontology and vocabulary standards like ICD, SNOMED, LOINC or UMLS. Current developments in this field are introduced in the following section. Closely related to integration aspects is data storage which ranges from DBMS- 
based centralized storage of all patient records to distributed concepts and document based approaches integrating vocabularies. To facilitate shared care, managed care or disease management, scalable, portable, distributed, and interoperable architectures are a prerequisite. Several research projects have implemented and evaluated architectures like e.g. the PropeR project [71] that developed an EPR system based on OMG HDTF specifications (www.omg.org/healthcare). The PING project proposed an open source personally controlled distributed electronic medical record system [72] based on XML-standards [73] and J2EE (http:// java.sun.com/javaee). The MUDR electronic health care record system is based on a 3-layer architecture using XML for communication between application layer and clients, and integrates a decision support system module as part of the application layer [74]. Further open source solutions for realising an EHR system are provided by openEHR (www.openehr.org) or OpenMRS (www.openmrs.org). The first represents a reference implementation for the corresponding EHR specifications, the latter focuses on developing a medical record system framework for developing countries.

\section{Current Developments in the Last Year (2006 up to the present)}

Recent research continues elaborating these architecture and technology related aspects of EPR systems. Advanced security infrastructures and security service structures have been analyzed and evaluated, with the conclusion that formal modelling of policies and policy bridging are the main challenges to be faced [75]. Techniques like end-to-end security [6] and e-consent based security [76] have gained further attention and research projects have implemented and evaluated standards-based security concepts for distributed EHR systems [77, 78].

Integration and especially semantic interoperability remains a problem and we therefore discuss it in the 'standards for interoperability' section in greater detail. But even if a great amount of partly competing standards for ensuring interoperability of EHR systems are available, there remains a "semantic gap" concerning standardized medical processes, which cannot be covered by current standards [79]. Lenz et al. underline the necessity of system evolution in system architectures and also in future integration standards.

Record storage concepts and implementation architectures have also been elaborated further. Proposing a model driven approach instantiating the ISO Reference Model for Open Distributing Processing (RM-ODP, ISO/IEC 10756-1) and based on a comparison of current approaches, Blobel concludes that a future-proof EHR architecture needs to be an open, flexible, scalable, useroriented, portable core application of health information systems and networks based on advanced architectural paradigms [80]. Regional and national initiatives are working towards implementing and introducing EHR architectures on a large scale (cf. e.g. [6, 81, 82], http:/ /www.nhscarerecords.nhs.uk). Web Services, SOAP, XML, HTTP, and CORBA are still used techniques for implementing EHR architectures ([74]). Additionally, IHE and its XDS profile are gaining increasing attention to prototype EHR architectures ([83]).

\section{Prospects}

Achieving semantic interoperability and the further development of corresponding standards and architectures will undoubtedly remain the most important topic for EPR and health information systems in general [84]. Additionally, the increasing importance of home care and telecare motivated in particular by demographic trends [85] impose new requirements for EPR systems. Sensor based ubiquitous computing technologies are essential for home and telecare [86]. HIS architectures on their way towards regional, national and global solutions face the challenge of integrating these technologies [87] - and so do EPR systems as their innermost component. Thus future work will focus on integrating corresponding data categories consistently and in semantically meaningful ways $[88,89]$. Based on the definition of Shabo [40, 41] a resulting EHR would aggregate “... recordings created by all healthcare enterprises from which the subject of the lifetime record has received medical care throughout his/her life" enhanced by the data coming from sensors in home care and telemonitoring systems.

\subsection{Standards for Semantic Interoperability of EPR Systems State of the Art}

To achieve semantic interoperability between institution-wide EPR, EHR, and also Personal Health Record systems (and not only between one particular implemented system and another), it is pivotal that appropriate standards are adopted throughout the health system. Some of these standards exist, others are currently under development by national and international Standards Development Organisations (SDOs) like the International Organization for Standardization (ISO), European Committee for Standardization (CEN), HL7, the American National Standards Institute (ANSI), and Standards Australia.

It is increasingly being recognized that standards are required on different levels, including, but not limited to the following:

- basic data types, 
- messages and services,

- architectures for EPR systems and knowledge-enabled computing,

- clinical terminologies (ontologies of reality),

- clinical content, including its structure (ontologies of information),

- scope, functionality and requirements of EPR systems,

- presentation of clinical concepts.

As an example, HL7 version 3 and other approaches like OMG's CORBA 3, openEHR and CEN EN 13606 "Electronic Health Record Communication" are maturing as architectural approaches for semantic interoperability [53]. When originally drafted several years ago, the EN 13606 reference model and archetype model were almost identical to those then being proposed for openEHR; however, in the intervening period openEHR has continued to develop through use in implementations around the world.

The selection of these standards should be adopted at the very least on a national level within a comprehensive standards framework. Also, compliance needs to be ensured. The 'Integrating the Healthcare Enterprise' (IHE) initiative and the Australian Healthcare Messaging Laboratory (AHML) ${ }^{1}$, have gained considerable momentum over the last year, increasing compliance and the real-world usefulness of standards.

\section{Current Developments in the Last Year (2006 up to the present)}

In the following, we describe recent developments in the different levels of standards important for EPR system development.

- Standardized basic data types: Standardized basic data types that can

\footnotetext{
The Australian Healthcare Messaging Laboratory (AHML) is a messaging certification laboratory for technical evaluation and certification of electronic messages in healthcare applications (especially HL7), established by the Collaborative Centre for eHealth (CCeH), University of Ballarat, Australia.
}

be used in EPR systems are for example defined in ISO 11404 as language-independent data types for programming languages; these data types provide an initial solid basis for standardization, but it is now increasingly recognised that a comprehensive harmonization and standardization of health data types is required to enable interoperability in health. Such specifications do not attempt to redefine or replace the definitions of real in ISO 11404, but build on the already defined functionality. In general, convergence of existing data type standards into a common set of data types for health remains a major ongoing goal, that is difficult to achieve. However, recently, both CEN and ISO seem to be increasingly receptive to considering the HL7 v3 UML ITS (implementation technology specification) data types, which are being developed with openEHR data types as the key input (cp. [90]). The following may serve as an exemplar for the problems that arise without harmonized data types. For the data types that support CEN EN 13606, CEN so far chose not to use the openEHR data types, but to create a new data types specification based on the HL7 v3 data types, with a number of modifications to deal with some criticisms of the HL7 v3 data types [91]. The problem with this is twofold. From the perspective of 13606 , the data types are not tailored to the 13606 reference model the way that the openEHR data types are, and from the perspective of HL7, the data types are an improper implementation of the HL7 v3 data types.

- Messaging and services: The various sub-versions of HL7 v2.x remain the standard for messaging and services in the health community, although much proprietary exchange of data remains, especially in less developed countries. In addition standards for special usages like the DICOM standard are increasingly being used. With regard to service-oriented architec- tures the Service Orientated Architecture and Healthcare Services Specification Project (HSSP, http:// hssp. wikispaces.com), a joint HL7 and Object Management Group (OMG) initiative has recognized the need for specifications for services to support healthcare IT as part of national infrastructures, which will result in both HL7 and OMG standards.

- Architectures for Electronic Health Records and knowledge-enabled computing: The past year has seen intensive discussion on this subject. Some see HL7 v3 RIM as the solution to this (e.g. [92]), other argue that the RIM will never be stable, is barely usable, ontologically deeply flawed, and in any case not an architecture for EHRs (e.g. [93]). Some argue that the combination of HL7 v3 with the Clinical Document Architecture (CDA) will lead to good results, as CDA makes v3 usable (e.g. [94]). Others argue that a comprehensive standard is needed that should be based on the specifications developed by the openEHR foundation (www. openEHR.org). The openEHR specifications are a major input to standards such as CEN EN 13606. The year 2007 has seen the release of openEHR 1.0.1, which provides a comprehensive platform for knowledge-based computing in healthcare, including but not limited to EHRs. The CEN 13606 archetype paradigm and reference model is very closely based on openEHR. There are some small differences in the reference model and CEN 13606 is focused on EHR extract exchange rather than specifying a complete EHR system which is the focus of openEHR.

- Clinical terminologies (ontologies of reality): Apart from - for example - the Unified Medical Language System (UMLS) and the International Classification of Diseases (ICD, especially ICD 10), SNOMED Clinical Terms, is a major player in this area (cf. e.g. [95, 96]). Although, some problems remain with its use, it is increasingly recognized, used, 
and recommended or mandated for national use in various countries. Recently, a dedicated Standards Development Organisation (SDO) for the maintenance, development, quality assurance and release of SNOMED CT has been established. A broad range of clinical terminology systems have been developed with an equally broad range of purposes and features. To be able to compare these, Cornet et al. have published a framework to describe the features of terminology systems [97].

- Clinical content, including its structure (ontologies of information): The last year has brought overwhelming agreement that in order to enable semantic interoperability, it is paramount to get the clinical content right in the first place. This requires intensive discussion of clinical content with clinicians of various disciplines to ensure that their complex needs are met in a comprehensive way. The concept of archetypes is increasingly seen as the appropriate means of actively engaging clinicians in the modelling of clinical content that suits their needs as archetypes uniquely separate the definition of clinical content from any technical concerns (like e.g. the use of the appropriate basic data types and many others). Some prefer to refer to these models more generically as 'clinical content models' or something similar. Regardless, the basic idea is well agreed on. It is formalized for example in the openEHR archetypes - archetypes which are formally based on the openEHR specifications, including the openEHR Reference Model and Archetype Model. The joint HL7/ openEHR Detailed Clinical Modelling group has also picked this up, as well as the UK Connecting for Health initiative of the National Health Service (NHS), recently producing hundreds of openEHR archetypes for their priority areas, all available online at http://www. openEHR. org and http:/ /www. archetypes.com. au. It also is increasingly being recognized that the development of clinical content models or archetypes requires what we refer to as 'flexible standardization' - i.e. that archetypes can safely evolve when clinical knowledge changes or a better or more comprehensive representation of a clinical concept (like e.g. 'blood pressure measurement') can be agreed on. The differences in the development processes of standards and archetypes are discussed by Hovenga and colleagues in [98]. Clinical content models seem to be the only feasible means of enabling semantic interoperability across language borders, as with clinical content models, the translation can occur within the context of the clearly defined clinical concept only, greatly improving the appropriateness and accuracy of the translation. It is important to note that clinical content models can (and should) reference clinical terminologies, and thus dramatically increase the usability as well as potential usages of clinical terminologies (e.g. [55]).

- Scope, Functionality, and Requirements of EHRs: Various efforts have been undertaken to more formally describe the scope, desired functionality and requirements of EHRs: For example, ISO Technical Report 20514 provides a classification of electronic health records as well as supporting descriptions of the scope and characteristics of electronic health records and record systems. ISO Technical Specification 18308 - currently under periodical review ${ }^{2}$ - describes the requirements for an

Most standards require periodic revision as there are many factors (like technological evolution) that may cause a standard to be out of date. Consequently, ISO reviews technical specifications after a period of 3 years and upon completion of the review will decide whether the technical specification will be revised, confirmed or withdrawn. If the technical specification is confirmed, it is reviewed again after a further 3 years, at which time it must be transformed into an international standard or be withdrawn. electronic health record architecture. The HL7 EHR system functional model, which was approved in 2004 as a Draft Standard for Trial Use (DSTU), has undergone a series of enhancements in 2006 and is now a fully approved American National Standards Institute (ANSI) standard. At the time of writing it is also on the ballot as a new work item for ISO.

- Presentation of clinical concepts: Not too much work has been undertaken in a standards environment to enable reliable and consistent presentation of clinical concepts in EPRs, which in turn is believed to have the potential to prevent clinical errors and improve patient safety. One notable exception is the Standards Australia work item IT/ 14/2 on 'Clinical concept presentation', currently under development.

The recognition that various communities must collaborate intensively is another trend that has increased considerably the past year. While ISO, CEN, HL7, openEHR as well as national standards organisations collaborate (including the possibility to 'fast-track' standards where applicable), standardization stakeholders like the health ICT vendor community have called for greater collaboration and cooperation between international SDOs to ensure that available standards are complementary rather than duplicative and competitive. One step towards this was taken at the 2006 Geneva Joint Working Group meeting with the signing of a broad agreement between ISO TC215, CEN TC251 and HL7 (see e.g. [99]). Also Ferranti et al. [100] argue in their comparison of CDA and the Continuity of Care Record (CCR) by the American Society for Testing and Materials (ASTM international) that competition among SDOs is counterproductive. They suggest to express CCR data elements with CDA syntax and "... to combine the CCR-defined set of data ele- 
ments with the CDA's method for expressing clinical documents".

\section{Prospects}

One of the major problems to be solved in the coming years, is that many published standards in health informatics as well as standards under development overlap in scope without clearly defining their boundaries or scope of application. While efforts exist to define mechanisms for 'converting' from one standard to another, it is increasingly being realised that harmonization of standards is needed. Without this, standards in the end will undermine their very purpose: to provide guidance and consistency.

Other trends include the development of metadata registries like METeOR (http:/ /meteor.aihw.gov.au), Australia's repository for national data standards for health, based on sound metadata principles. With the myriad of standards available, nations are currently challenged to ensure that a comprehensive and detailed standards framework is in place to ensure that clear guidance is given to vendors and other players in healthcare. For maximum value, it should be ensured that standards as well as nationwide standard frameworks are based primarily on scientific merit, not political issues. Often the use of standards is voluntary and incentives may need to be provided for their adoption.

For instance, the standardization of clinical content has to be flexible and governed by different principles than the development of a standard for basic data types since clinical knowledge changes quite frequently. Nonetheless, it is required to adhere to strict version control whenever 'incompatible' changes are agreed on. Domain Knowledge Governance [98] with broad input from all stakeholders is required to achieve this, rather than the formal definition of a 'Clinical Content Standard'.
One challenge to be overcome is the fact that the development of standards in health care is often a chicken and egg problem. Standards need to be proven in practice before they should become a standard, however, it is very challenging to convince vendors to adopt and implement a specification that may or may not become a standard sometime in the future - as resources needed for the adoption as well as the long-term implications of this adoption are usually high. As reult, it is common for insufficient feedback to be given during a standards development process. This is where open specifications like the ones developed by the openEHR foundation can be very useful.

All in all, we believe that the coming years will see further implementation, comparison and evaluation of the various standards leading to more harmonization and a clearer scope of application of the various standards. It is also expected that appropriate mechanisms, tools and presentations will increase the usability of clinical terminologies such as SNOMED CT.

\subsection{Integration of EPR Systems in the HIS as Integral Part of the Workflow, the Billing and the Logistic Management}

\section{State of the Art}

After the above review of architectures and technologies for implementing EPR-systems and standards for semantic interoperability among various EPR systems, we can see that there is an increasing number of commercial EPR available, which implement standards or which are built using open information models. Unfortunately, EPRs are often considered to be more or less independent from the rest of a hospital information system. HIS are traditionally viewed as been made of large pillars, such as logistics, billing, human resources, electronic patient record and PACS. Achieveing really efficient care requires integrating the resources (human, competences and logistics), the management (including finances and billing) and the patient information into one coherent organization centered on the processes and the workflows for the missions of the hospital, and which also should include research and teaching ([101], p. 24). Logistics is the art and the science of managing and controlling the flow of objects, actors, energy, information and all other resources involved, including locations, from the source of production to the end user. Logistics is recognized as a major component for any marketing or manufacturing to suceed, though it is still mostly left out of the health care industry when it comes to providing care. Logistics involves the integration of information, people, objects and their transformations at the lowest cost possible, with the highest efficiency. Surprisingly, the term "logistics" does not exist per se in the Medical Subject headings of the NLM Medline but only as one of the entry terms of 'organization and administration', introduced in 1968. Looking at the literature around EPR and interoperability, it is striking to see how much scientific work has been done around interoperability at the clinical level, sharing medical information between care providers, systems, in community networks, and how little work has been published around the integrated healthcare system as a whole. Within care facilities, little has been done to model the needs and expectations of consolidated information systems, such as the care and resources needed to achieve them. Most theoretical work concentrates on global architectural designs or functional needs, mostly around redundancy, functional correspondence, informational redun- 
Knaup et al.

dancy or degree of heterogeneity [102105], while most pragmatic implementations do link direct care and billing, especially in the fee for services reimbursement models.

Reviewing the benefits and costs of EPR systems and the need for information systems strategic planning in order to adapt their functionality and quality to the needs of health care organizations has become more in focus these last years: help for efficient care and cost efficiency are prerequisites [106-111].

\section{Current Developments in the Last Year (2006 up to the present)}

Most of the recently published work around integrated clinical information systems and patient records have focused on technical aspects, such as web technologies, tele-monitoring and standards, or on strategic aspects, including management, governance and clinical research [3, 87, 112-118]. Literature about logistics and care is rare with some important exceptions, such as tracking using RFID and workflows. Location tracking systems for people, devices and drugs are becoming more prevalent in clinical settings, but applications are still uncommon [119, 120]. A noticeable event occurred about RFID in 2006: to our knowledge, the first publication on the human implantable RFID chip and its security, which appears very controversial and insufficient [121]. Another domain that attracts increasing attention is related to workflow integrated with clinical data [122, 123]. By putting together tracking, workflow and clinical integration technologies, some authors propose a vision of disruptive new environments [124].

\section{Propects}

Widespread interest in the challenging topic of integration is helping raise awareness of interoperability to aid in integrating the healthcare enterprise, at the highest level. Maximizing usage resources efficiency, improved logistics, optimal scheduling, there are many sectors that will allow important cost optimization and quality improvement just by considering a care facility as a production industry that has to be optimized. Traceability is another important issue that has still received very little attention in healthcare. Traceability will be one of the major focuses of large industries in the next years, at a global level, not only from a safety or a legal point of view but also in order to increase the efficiency of supply chains. Care providers and healthcare facilities are at the crossing roads of many supply industries, pharmaceuticals, medical devices, disposable products, implantable devices to quote the most evident, but also numerous other suppliers, such as food and groceries, beds, clothes, computers, office etc. Every hospital is like a small industry with distributed stocks management and an internal market, embedded in the global market. Improving this management through greater visibility, accuracy and speed might lead to the same improvement in economic efficiency as it has been experienced in other industries. Looking at the EPR as the central industry in health care, embedded in the logistics of care and the management of care is no longer blasphemous.

\section{Discussion}

The past few years have seen a myriad of developments and deployments of EPR and EHR systems. This was possible due to continuing success of resarch in data privacy and data security, but also on some significant return on investment demonstrations [106]. The majority of EPR-systems are still legacy and fragmented, some are institution-wide, oth- ers have very limited focus. There are rare examples of systems on a regional scale, and very few initiatives are underway to establish nationwide shared EHRsystems. A first step to realize them might be the exchange of electronic documents $[6,125]$. Other steps might be unique identifiers, which is very challenging topic with a lot of privacy concerns.

But, as stated earlier, we are still a long way from EPR systems that can flexibly satisfy all user requirements. Especially, semantic interoperability has to be achieved to avoid double data entry and better integration in local workflows. This covers organisational transactions like those supported by the IHE initiative as well as the individual workflow of the clinical user.

Although defining failure and success of a health information system (HIS) in general is complex, and the "best current estimate is that HIS failure is an important problem" [126], we can safely say that in their current form EPR and EHR-systems have proven to be rarely sustainable for various reasons. Inhibitors and enablers of sustainability include clinical, technical, sociotechnical, as well as political \& business factors. According to Haux, a lot of research and application is necessary to further develop and investigate HIS architectures and infrastructures, in order to identify sustainable approaches [87]. In order to increase sustainability of these systems a solution may be to focus on defining and maintaining sustainable 'Health Informatics' building blocks or components that are motivated by a high-level framework. This includes standards with clear scope that are not overlapping, but clearly build on each other. These components need to be easily updatable when clinical knowledge changes, easily adaptable when business requirements or processes change, and easily exchangeable when technology advances. 
This is the reason, for our focus on standardization efforts in this survey. The authors strongly support initiatives that leverage interoperability at all levels. Shared care implies that EPR-systems must be truly interoperable. Health data exchange via messages may not be enough: a standard logic system architecture is required. This need is now realised by a variety of standardizing committees. The efforts of the various SDO to work together in trying to harmonize their work assume synergetic effects if they are to result in a widespread consensus standard for EPR systems architecture, functions and terminology. The development and adoption of standards has many advantages, but also some disadvantages. For example, the development of standards is a rather slow process that is based on consensus, rather than on excellence. Standards development is most valuable when consensus is required in chossing among several clear, existing alternatives, the scope and complexity is relatively limited, adoption relatively simple, and full potential can only be unleashed when everybody agrees to adhere to a common denominator. In the case of health informatics, complexity is sometimes so high that useful standards can only be created with validation via implementation, and a recognized feedback path into the standards process. Initially, it may be required to employ open community based development of specifications, including their validation by real world implementation experience. These specifications can finally serve as the input for the development of a standard. The openEHR foundation for example - while not producing formal standards per se - is involved in health standards work in Europe (CEN TC/ 251) and internationally (HL7 and ISO). However, openEHR specifications are perfected over time by ongo- ing implementation experience and community feedback. The results of all the work are fed back into the openEHR specifications and made available to standards bodies.

As an example, a standard is currently under development to enable the transmission of archetyped clinical data within HL7 v2.x messages, thus reducing the need for HL7's Z-segments, which users of the standard may define for their own purposes (cf. Standards Australia IT 14-6 Project 7355 Representing archetypes and EHR Data in HL7 Version 2 - currently in $2^{\text {nd }}$ draft Stage). Nevertheless, there are several examples of successful application of standards. For example, HL7 v2.x has to be regarded as one of the most successful standards in health care: Despite all the problems that remain, HL7 v2 has done a great deal to solve many problems with regard to information exchange in health care. Also, DICOM is established as digital format for image databases and for exchange among modalities and PACS. When standards for semantic interoperability are available and are used, using health data for multiple purposes will come within reach. Health data are not only relevant for clinical purposes, but also for clinical research, clinical bioinformatics, quality management and health reporting.

It is promising to see how much scientific work has been done around interoperability at the clinical level, sharing medical information between care providers, systems and in community networks. Nevertheless, only few articles have been published about the integrated healthcare system as a whole. Regional health information organizations and shared electronic health records are expected to have an important impact on the practice of medicine, medico-economic efficiency and quality of care. They can be extended to states and across countries, to improve mobility, the safety and public health efforts, including bio-surveillance and disaster management response. Such large networks will allow building large databases of deidentified data for clinical and transitional research [127-129].

\section{Proscpects}

There is increasing discussion about ehealth and the EHR, although there is no consensus on the definition of the two concepts. Nevertheless, there is consensus on the need to empover the patient as a partner in healthcare. Empowering goes far beyond just giving access to information in the record. It must involve building an understandable system that encourages respect towards, and commitment by all stakeholders. Each health care professional (e.g. nurse, physician, physiotherapist amongst many others) needs a contextualized view and the patient especially needs an understandable and emotionally acceptable system. In this context interface terminologies have to be further discussed [130]. Since patients need an individualized view on their health data, patients' attitudes and capabilities have to be considered in the design process of EHR-systems.

All this will result in enormous quantities of data, in distributed and maybe virtualized databases. It will be increasingly difficult to identify pertinent knowledge and information. This means, that a time when medical informatics is still struggling to store all data in a patient-centered EHR, the time is upon us to think about how it may be possible to keep only relevant data in the EHR and how to present it.

There is still a conflict of interest between recording and analyzing data [131]. For automatic analysis a high degree of standardization is necessary. Nevertheless, health care professionals still prefer to record data in less than 
standardized ways. They feel it is more expressive to use natural language. Therefore, approaches for natural language processing and text mining [132] remain an important issue of research to increase usability in clinical practice and for research and management. Examples are the detection of adverse events [133] or the extraction of medical problems [134] from narrative text where promising results have been reported. The challenge is to find a balance between sufficient specifity and sensitivity so that these approaches can be used to support management and clinical processes reliably in routine practice. Also the applicability for clinical research has to be explored [135].

Decades of research on decision support resulted in knowledge-based functions that can be integrated into EPR-systems. The most discussed application in the last few years is computerized physician order entry (CPOE, [108, 136-138]).

These considerations show, that modelling the clinical content, preferably in a standardized format could be the basis for analysis, decision support, and all knowledge-enabled computing. The future will show if archetypes are really an appropriate and efficient means for multi-purpose usage of health data.

\section{References}

1. Oh H, Rizo C, Enkin M, Jadad A. What is eHealth (3): a systematic review of published definitions. J Med Internet Res 2005;7(1):el.

2. Ahern DK, Kreslake JM, Phalen JM. What is eHealth (6): perspectives on the evolution of eHealth research. J Med Internet Res 2006;8(1):e4.

3. Moehr JR, Schaafsma J, Anglin C, Pantazi SV, Grimm NA, Anglin S. Success factors for telehealthA case study. Int J Med Inform 2006 Oct-Nov;75(1011):755-63.

4. Hernandez V, Blanquer I. The Grid as a healthcare provision tool. Methods Inf Med 2005;44(2):144-8.

5. van Bemmel JH, Musen MA. Handbook of Medical Informatics. Heidelberg: Springer; 1997.

6. SchabetsbergerT, Ammenwerth E, Andreatta S, Gratl G, Haux R, Lechleitner G, et al. From a paperbased transmission of discharge summaries to electronic communication in health care regions. Int $\mathrm{J}$
Med Inform 2006 Mar-Apr;75(3-4):209-15.

7. Knaup P, Pilz J, Kaltschmidt J, Ludt S, Szecsenyi J, Haefeli WE. Standardized documentation of drug recommendations in discharge letters - a contribution to quality management in cooperative care. Methods Inf Med 2006;45(4):336-42.

8. Ford EW, Menachemi N, Phillips MT. Predicting the adoption of electronic health records by physicians: when will health care be paperless? J Am Med Inform Assoc 2006 Jan-Feb;13(1):106-12.

9. Ammenwerth E, Iller C, Mahler C. IT-adoption and the interaction of task, technology and individuals: a fit framework and a case study. BMC Med Inform Decis Mak 2006;6:3.

10. Gans D, Kralewski J, Hammons T, Dowd B. Medical groups' adoption of electronic health records and information systems. Practices are encountering greater-than-expected barriers to adopting an EHR system, but the adoption rate continues to rise. Health Aff (Millwood) 2005 SepOct;24(5):1323-33.

11. Bates DW. Physicians and ambulatory electronic health records. U.S. Physicians are ready to make the transition to EHRs - which is clearly overdue, given the rest of the world's experience. Health Aff (Millwood) 2005 Sep-Oct;24(5):1180-9.

12. Nohr C, Andersen SK, Vingtoft S, Bernstein K, Bruun-Rasmussen M. Development, implementation and diffusion of EHR systems in Denmark. Int J Med Inform 2005 Mar;74(2-4):229-34.

13. Reicher J, Reicher D, Reicher M. Use of Radio Frequency Identification (RFID) Tags in Bedside Monitoring of Endotracheal Tube Position. J Clin Monit Comput 2007 Apr 4.

14. Jiang M, Xing B, Sun Z, Fu P, Chen H, Chen M, et al. A Dynamic Blood Information Management System Based on RFID. Conf Proc IEEE Eng Med Biol Soc 2005;1:546-9.

15. Walker J, Pan E, Johnston D, Adler-Milstein J, Bates DW, Middleton B. The Value Of Health Care Information Exchange And Interoperability. Health Aff (Millwood) 2005 Jan 19.

16. Narayan D. Empowerment. J Ambul Care Manag 2007 Apr-Jun;30(2):120-5.

17. Ma C, Warren J, Phillips P, Stanek J. Empowering patients with essential information and communication support in the context of diabetes. Int J Med Inform 2006 Aug;75(8):577-96.

18. Tuil WS, Verhaak CM, Braat DD, de Vries Robbe $\mathrm{PF}, \mathrm{Kremer}$ JA. Empowering patients undergoing in vitro fertilization by providing Internet access to medical data. Fertil Steril 2007 Apr 6; Epub ahead of print.

19. Leiner F, Gaus W, Haux R, Knaup-Gregori P. Medical Data Management - A Practical Guide. New York: Springer; 2003.

20. Tang PC, Ash JS, Bates DW, Overhage JM, Sands DZ. Personal health records: definitions, benefits, and strategies for overcoming barriers to adoption. J Am Med Inform Assoc 2006 Mar-Apr;13(2):121-6.

21. Thompson W, Dodek PM, Norena M, Dodek J. Computerized physician order entry of diagnostic tests in an intensive care unit is associated with improved timeliness of service. Crit Care Med 2004 Jun;32(6):1306-9.

22. Walker I, Sigouin C, Sek J, Almonte T, Carruthers J, Chan A, et al. Comparing hand-held computers and paper diaries for haemophilia home therapy: a randomized trial. Haemophilia 2004 Nov;10(6):698-704.

23. Knaup P. Electronic Patient Records and their Benefit for Patient Care. Methods Inf Med 2006;45 Suppl 1:40-2.

24. Jaspers MW, Knaup P, Schmidt D. The computerized patient record: where do we stand ? Methods Inf Med 2006;45 Suppl 1:29-39.

25. Varpio L, Schryer CF, Lehoux P, Lingard L. Working off the record: physicians' and nurses' transformations of electronic patient record-based patient information. Acad Med 2006 Oct;81(10 Suppl):S35-9.

26. Cheek J, Gillham D, Mills P. Use with care: possibilities and constraints offered by computers in nursing clinical education. Int J Med Inform 1998;50:111-5.

27. Cruz-Correia R, Vieira-Marques P, Ferreira A, Oliveira-Palhares E, Costa P, Costa-Pereira A. Monitoring the integration of hospital information systems: How it may ensure and improve the quality of data. Stud Health Technol Inform 2006;121:176-82.

28. Patel VL, Kaufman DR, Allen VG, Shortliffe EH, Cimino JJ, Greenes RA. Toward a framework for computer-mediated collaborative design in medical informatics. Methods Inf Med 1999 Sep;38(3):158-76.

29. Gerdsen F, Müller S, Jablonski S, Prokosch HU. Standardized exchange of clinical documents- towards a shared care paradigm in glaucoma treatment. Methods Inf Med 2006;45(4):359-66.

30. van der Haak M, Mludek V, Wolff AC, Bülzebruck H, Oetzel D, Zierhut D, et al. Networking in Shared Care - First Steps towards a Shared Electronic Patient Record for Cancer Patients. Methods Inf Med 2002;41:419-25.

31. de Groen PC, Barry JA, Schaller WJ. Applying World Wide Web Technology to the Study of Patients with Rare Diseases. Ann Intern Med 1998;129:107-13.

32. Rahman M, Morita S, Fukui T, Sakamoto J. Physicians' choice in using Internet and fax for patient recruitment and follow-up in a randomized controlled trial. Methods Inf Med 2004;43(3):268-72.

33. Missinou MA, Olola CH, Issifou S, Matsiegui PB, Adegnika AA, Borrmann S, et al. Short report: Piloting paperless data entry for clinical research in Africa. Am J Trop Med Hyg 2005 Mar;72(3):301-3.

34. McDonald CJ, Overhage M, Dexter P, Takesue BY, Dwyer D. A Framework for Capturing Clinical Data Sets from Computerized Sources. Ann Intern Med 1997;127:675-82.

35. El Emam K, Jabbouri S, Sams S, Drouet Y, Power M. Evaluating common de-identification heuristics for personal health information. J Med Internet Res. 2006;8(4):e28.

36. Kalra D. Electronic health record standards. Methods Inf Med 2006;45 Suppl 1:136-44.

37. Souhami R. Governance of research that uses identifiable personal data. BMJ 2006 Aug 12;333(7563):315-6.

38. Walley T. Using personal health information in medical research. BMJ 2006 Jan 21;332(7534):130-1.

39. Dorr DA, Phillips WF, Phansalkar S, Sims SA, Hurdle JF. Assessing the difficulty and time cost of de-identification in clinical narratives. Methods Inf Med 2006;45(3):246-52.

40. Shabo A. A global socio-economic-medico-legal model for the sustainability of longitudinal electronic health records. Part 1. Methods Inf Med 
Electronic Patient Records: Moving from Islands and Bridges towards Electronic Health Records for Continuity of Care

2006:45(3):240-5

41. Shabo A. A Global Socio-economic-medico-legal Model for the Sustainability of Longitudinal Electronic Health Records - Part 2. Methods Inf Med 2006;45(5):498-505.

42. Sax U, Schmidt S. Integration of genomic data in Electronic Health Records - opportunities and dilemmas. Methods Inf Med 2005;44(4):546-50.

43. Kakazu KK, Cheung LW, Lynne W. The Cancer Biomedical Informatics Grid (caBIG): pioneering an expansive network of information and tools for collaborative cancer research. Hawaii Med J 2004 Sep;63(9):273-5.

44. Hanauer DA, Rhodes DR, Sinha-Kumar C, Chinnaiyan AM. Bioinformatics approaches in the study of cancer. Curr Mol Med 2007 Feb;7(1):133-41.

45. Saltz J, Oster S, Hastings S, Langella S, Kurc T, Sanchez W, et al. caGrid: design and implementation of the core architecture of the cancer biomedical informatics grid. Bioinformatics $2006 \mathrm{Aug}$ 1;22(15):1910-6

46. Phillips J, Chilukuri R, Fragoso G, Warzel D, Covitz PA. The caCORE Software Development Kit: streamlining construction of interoperable biomedical information services. BMC Med Inform Decis Mak 2006;6:2

47. Tobias J, Chilukuri R, Komatsoulis GA, Mohanty $\mathrm{S}$, Sioutos N, Warzel DB, et al. The CAP cancer protocols - a case study of caCORE based data standards implementation to integrate with the Cancer Biomedical Informatics Grid. BMC Med Inform Decis Mak 2006;6:25.

48. Pare G, Jaana M, Sicotte C. Systematic review of home telemonitoring for chronic diseases: the evidence base. J Am Med Inform Assoc 2007 MayJun;14(3):269-77.

49. Meystre S. The current state of telemonitoring: a comment on the literature. Telemed J E Health $2005 \mathrm{Feb} ; 11(1): 63-9$.

50. Revere D, Turner AM, Madhavan A, Rambo N, Bugni PF, Kimball A, et al. Understanding the information needs of public health practitioners: A literature review to inform design of an interactive digital knowledge management system. J Biomed Inform 2007 Jan 11.

51. Noone J, Warren J, Brittain M. Information overload: opportunities and challenges for the GP's desktop. Medinfo. 1998;9 Pt 2:1287-91.

52. Quaglini S. Information models for data sharing. Neurol Sci 2006 Jun;27 Suppl 3:S281-3.

53. Blobel BG, Engel K, Pharow P. Semantic interoperability-HL7 Version 3 compared to advanced architecture standards. Methods Inf Med 2006; 45(4):343-53.

54. Rothschild AS, Lehmann HP. Information retrieval performance of probabilistically generated, problem-specific computerized provider order entry picklists: a pilot study. J Am Med Inform Assoc 2005 May-Jun;12(3):322-30.

55. Sundvall E, Nyström M, Forss M, Chen R, Petersson $\mathrm{H}$, Åhlfeldt H. Graphical Overview and Navigation of Electronic Health Records in a prototyping environment using Google Earth and openEHR Archetypes. Accepted to Medinfo 2007. 2007.

56. Ruotsalainen P. Security requirements in EHR systems and archives. Stud Health Technol Inform 2004;103:453-8.

57. Pharow P, Blobel B. Security infrastructure ser- vices for electronic archives and electronic health records. Stud Health Technol Inform 2004:103:434-40

58. Georgiadis CK, Mavridis IK, Pangalos GI. Healthcare teams over the Internet: programming a certificate-based approach. Int J Med Inform 2003 Jul; 70(2-3):161-71.

59. Pharow P, Blobel B. Security infrastructure requirements for electronic health cards communication. Stud Health Technol Inform 2005;116:403-8.

60. Ash JS, Berg M, Coiera E. Some unintended consequences of information technology in health care: the nature of patient care information system-related errors. J Am Med Inform Assoc 2004 MarApr;11(2):104-12.

61. Norgall T. Interoperability—a key infrastructure requirement for personalised health services. Stud Health Technol Inform 2005;117:125-33.

62. Hinchley A. Understanding. A primer on the HL7 Version 3 Communication Standard. Köln: Alexander Mönch Verlag; 2005.

63. Dolin RH, Alschuler L, Beebe C, Biron PV, Boyer SL, Essin D, et al. The HL7 Clinical Document Architecture. J Am Med Inform Assoc 2001 NovDec;8(6):552-69.

64. Kalra D, Beale T, Heard S. The openEHR Foundation. Stud Health Technol Inform 2005;115:153-73.

65. Schweiger R, Brumhard M, Hoelzer S, Dudeck J. Implementing health care systems using XML standards. Int J Med Inform 2005 Mar;74(2-4):267-77.

66. Spyrou SS, Berler AA, Bamidis PD. Information system interoperability in a regional health care system infrastructure: a pilot study using health care information standards. Stud Health Technol Inform 2003;95:364-9.

67. Bludau HB, Wolff A, Hochlehnert AJ. Presenting XML-based medical discharge letters according to CDA. Methods Inf Med 2003;42(5):552-6.

68. Goossen WT, Jonker MJ, Heitmann KU, Jongeneelde Haas IC, de Jong T, van der Slikke JW, et al. Electronic patient records: domain message information model perinatology. Int J Med Inform 2003 Jul;70(2-3):265-76.

69. Muller ML, Uckert F, Burkle T, Prokosch HU. Cross-institutional data exchange using the clinical document architecture (CDA). Int J Med Inform 2005 Mar; 74(2-4):245-56.

70. van der Linden H, Tange H, Talmon J, Hasman A. PropeR revisited. Stud Health Technol Inform 2003;95:346-51.

71. van der Linden H, Boers G, Tange H, Talmon J, Hasman A. PropeR: a multi disciplinary EPR system. Int J Med Inform 2003 Jul; 70(2-3):149-60.

72. Simons WW, Mandl KD, Kohane IS. The PING personally controlled electronic medical record system: technical architecture. JAm Med Inform Assoc 2005 Jan-Feb;12(1):47-54.

73. W3C. Extensible Markup Language (XML). [cited 20.04.2007]; Available from: http://www.w3.org/ $\mathrm{XML} /$

74. Hanzlicek P, Spidlen J, Heroutova H, Nagy M. User interface of MUDR electronic health record. Int J Med Inform 2005 Mar;74(2-4):221-7.

75. Blobel B. Comparing approaches for advanced ehealth security infrastructures. Int J Med Inform 2007 May-Jun;76(5-6):454-9.

76. Bergmann J, Bott OJ, Pretschner DP, Haux R. An econsent-based shared EHR system architecture for integrated healthcare networks. Int J Med Inform 2007 Feb-Mar;76(2-3):130-6.

77. Sucurovic S. Implementing security in a distributed web-based EHCR. Int J Med Inform 2007 May-Jun;76(5-6):491-6.

78. Boniface M, Watkins ER, Saleh A, Dogac A, Eichelberg M. A secure semantic interoperability infrastructure for inter-enterprise sharing of electronic healthcare records. Stud Health Technol Inform 2006; 120:225-35.

79. Lenz R, Beyer M, Kuhn KA. Semantic integration in healthcare networks. Int J Med Inform 2007 FebMar;76(2-3):201-7.

80. Blobel B. Advanced and secure architectural EHR approaches. Int J Med Inform 2006 Mar-Apr;75(34):185-90.

81. Bernstein K, Bruun-Rasmussen M, Vingtoft S. A method for specification of structured clinical content in electronic health records. Stud Health Technol Inform 2006;124:515-21.

82. Giokas D. Canada Health Infoway - Towards a National Interoperable Electronic Health Record (EHR) Solution. Stud Health Technol Inform 2005; 115:108-40.

83. Wozak F, Ammenwerth E, Breu M, Penz R, Schabetsberger T, $\operatorname{Vog} 1 \mathrm{R}$, et al. Medical Data GRIDs as approach towards secure cross enterprise document sharing (based on IHE XDS). Stud Health Technol Inform 2006;124:377-83.

84. Kuhn KA, Wurst SH, Bott OJ, Giuse DA. Expanding the scope of health information systems. Challenges and developments. Methods InfMed 2006;45 Suppl 1:43-52.

85. Koch S. Home telehealth — current state and future trends. Int J Med Inform 2006 Aug;75(8):565-76.

86. Bott OJ, Ammenwerth E, Brigl B, Knaup P, Lang E, Pilgram R, et al. The challenge of ubiquitous computing in health care: technology, concepts and solutions. Findings from the IMIA Yearbook of Medical Informatics 2005. Methods Inf Med 2005;44(3):473-9.

87. Haux R. Individualization, globalization and health - about sustainable information technologies and the aim of medical informatics. Int J Med Inform 2006 Dec;75(12):795-808.

88. Chronaki CE, Chiarugi F. Interoperability as a quality label for portable \& wearable health monitoring systems. Stud Health Technol Inform 2005;117:108-16.

89. Walseth OA, Arsand E, Sund T, Skipenes E. Wireless transfer of sensor data into electronic health records. Stud Health Technol Inform 2005;116:334-9.

90. NHS Connecting for Health. Investigating implementing CEN 13606 with HL7 V3 and SNOMED CT - Final Report. 2006:http://detailedclinicalmodels. org/documents/NHS_CFH_13606InvestigationRpt v1-0.pdf, last accessed June 2007, 12th.

91. Martin-Sanchez F, Iakovidis I, Norager S, Maojo V, De Groen P, Van Der Lei J, et al. Synergy between medical informatics and bioinformatics: facilitating genomic medicine for future health care. $\mathrm{J}$ Biomed Inform $2004 \mathrm{Feb}$;37(1):30-42.

92. Schadow G, Mead CN, Walker DM. The HL7 reference information model under scrutiny. Stud Health Technol Inform 2006;124:151-6.

93. Smith B, Ceusters W. HL7 RIM: an incoherent standard. Stud Health Technol Inform 2006; 124:133-8.

94. Dolin RH, Alschuler L, Boyer S, Beebe C, Behlen 
Knaup et al.

FM, Biron PV, et al. HL7 Clinical Document Architecture, Release 2. J Am Med Inform Assoc 2006 Jan-Feb;13(1):30-9.

95. Schulz S, Hanser S, Hahn U, Rogers J. The semantics of procedures and diseases in SNOMED CT. Methods Inf Med 2006;45(4):354-8.

96. Richesson RL, Andrews J, Krischer J. Use of SNOMED CT to Represent Clinical Research Data: A Semantic Characterization of Data Items on Case Report Forms in Vasculitis Research. J Am Med Inform Assoc 2006 Jun 23.

97. Cornet R, de Keizer NF, Abu-Hanna A. A framework for characterizing terminological systems. Methods Inf Med 2006;45(3):253-66.

98. Hovenga EJS, Garde S, Carr T, Hullin CM. Innovative approaches and processes for capturing expert aged care knowledge for multiple purposes. electronic Journal of Health Informatics 2007;2(1):e5.

99. Standards Australia. Report on international standards meetings and HIMSS Europe, October-November 2006. Part 1 of 3 - Global Health Information Technology Standards Summit. 2006.

100. Ferranti JM, Musser RC, Kawamoto K, Hammond WE. The clinical document architecture and the continuity of care record: a critical analysis. J Am Med Inform Assoc 2006 MayJun;13(3):245-52.

101. Haux R, Winter A, Ammenwerth E, Brigl B. Strategic Information Management in Hospitals. An Introduction to Hospital Information Systems. New York: Springer; 2004.

102. Brigl B, Hubner-Bloder G, Wendt T, Haux R, Winter A. Architectural quality criteria for hospital information systems. AMIA Annu Symp Proc. 2005:81-5.

103. Ammenwerth E, Buchauer A, Haux R. A Requirements Index for Information Processing in Hospitals. Methods Inf Med 2002;41:282-8.

104. Hübner-Bloder G, Ammenwerth E, Brigl B, Winter A. Specification of a reference model for the domain layer of a hospital information system. Stud Health Technol Inform 2005;116:497-502.

105. Winter A, Brigl B, Wendt T. Modeling hospital information systems. Part 1: The revised threelayer graph-based meta model 3LGM2. Methods Inf Med 2003;42(5):544-51

106. Frisse M. IAIMS: planning for change. J Am Med Inform Assoc 1997 Mar-Apr;4(2 Suppl):S13-9.

107. Boyes A, Newell S, Girgis A. Rapid assessment of psychosocial well-being: are computers the way forward in a clinical setting? Qual Life Res 2002;11(1):27-35.

108. Kaushal R, Shojania KG, Bates DW. Effects of computerized physician order entry and clinical decision support systems on medication safety: a systematic review. Arch Intern Med 2003 Jun 23;163(12):1409-16.

109. Krohn R. In search of the ROI from CPOE. J Healthc Inf Manag 2003 Fall;17(4):6-9.

110. Garde S, Baumgarten B, Basu O, Graf N, Haux $\mathrm{R}$, Herold R, et al. A Meta-Model of Chemotherapy Planning in the Multi-Hospital / MultiTrial-Center-Environment of Pediatric Oncology. Methods Inf Med 2004;43:171-83.

111. Menachemi N, Brooks RG. Reviewing the ben- efits and costs of electronic health records and associated patient safety technologies. J Med Syst 2006 Jun;30(3):159-68.

112. Haux R. Health information systems - past, present, future. Int J Med Inform 2006 MarApr;75(3-4):268-81.

113. Müller H, Michoux N, Bandon D, Geissbuhler A. A review of content-based image retrieval systems in medical applications-clinical benefits and future directions. Int J Med Inf 2004 Feb;73(1):1-23.

114. Maudlin J, Keene J, Kobb R. A road map for the last journey: home telehealth for holistic end-oflife care. Am J Hosp Palliat Care 2006 OctNov;23(5):399-403.

115. Poh CL, Kitney RI, Shrestha RB. Addressing the future of clinical information systems-Webbased multilayer visualization. IEEE Trans Inf Technol Biomed 2007 Mar;11(2):127-40.

116. Schlag PM. On the Way to New Horizons: Telemedicine in Oncology. Oncologist 1997;2(2):III-IV

117. Turisco F, Keogh D, Stubbs C, Glaser J, Crowley $\mathrm{Jr}$ WF. Current status of integrating information technologies into the clinical research enterprise within US academic health centers: strategic value and opportunities for investment. J Investig Med 2005 Dec;53(8):425-33.

118. Kramer S. The doctor will see you now. Looking to cut costs and improve care, providers are turning to telehealth. Healthc Inform 2007 $\mathrm{Feb} ; 24(2): 48,50$.

119. Spahni S, Lovis C, Ackermann M, Mach N, Bonnabry P, Geissbuhler A. Guarantying the quality of chemotherapy: from the order to the administration. Stud Health Technol Inform 2006; 124:241-6.

120. Shea S, Weinstock RS, Starren J, Teresi J, Palmas W, Field L, et al. A randomized trial comparing telemedicine case management with usual care in older, ethnically diverse, medically underserved patients with diabetes mellitus. J Am Med Inform Assoc $2006 \mathrm{Jan}-\mathrm{Feb} ; 13(1): 40-51$.

121. Halamka J, Juels A, Stubblefield A, Westhues J. The security implications of VeriChip cloning. J Am Med Inform Assoc 2006 Nov-Dec; 13(6):601-7.

122. Lester J, Prady S, Finegan Y, Hoch D. Learning from e-patients at Massachusetts General Hospital. BMJ 2004 May 15;328(7449):1188-90.

123. Vishwanatham R. Citation analysis in journal rankings: medical informatics in the library and information science literature. Bulletin of the Medical Library Association 1998;86(4):518-22.

124. Sutherland LA, Campbell M, Ornstein K, Wildemuth B, Lobach D. Development of an adaptive multimedia program to collect patient health data. Am J Prev Med 2001;21(4):320-4.

125. Simons W, Halamka J, Kohane IS, Nigrin D, Finstein N, Mandl KD. Integration of the Personally Controlled Electronic Medical Record into Regional Inter-regional Data Exchanges: A National Demonstration. AMIA Annu Symp Proc. 2006:1099.

126. Heeks R. Health information systems: Failure, success and improvisation. Int J Med Inform 2006 Feb;75(2):125-37.

127. Shapiro JS, Kannry J, Lipton M, Goldberg E,
Conocenti P, Stuard S, et al. Approaches to patient health information exchange and their impact on emergency medicine. Ann Emerg Med 2006 Oct; 48 (4):426-32.

128. Barthell EN, Pemble KR. The National Emergency Medical Extranet project. J Emerg Med 2003 Jan;24(1):95-100.

129. Lagoe RJ, Westert GP. Community wide electronic distribution of summary health care utilization data. BMC Med Inform Decis Mak 2006;6:17.

130. Rosenbloom ST, Miller RA, Johnson KB, Elkin PL, Brown SH. Interface terminologies: facilitating direct entry of clinical data into electronic health record systems. J Am Med Inform Assoc 2006 May-Jun;13(3):277-88.

131. Hazlehurst B, Frost HR, Sittig DF, Stevens VJ. MediClass: A system for detecting and classifying encounter-based clinical events in any electronic medical record. J Am Med Inform Assoc 2005 standardized documentation structured data entry;12(5):517-29.

132. Li Q, Wu YF. Identifying important concepts from medical documents. J Biomed Inform 2006 Dec;39(6):668-79.

133. Melton GB, Hripcsak G. Automated detection of adverse events using natural language processing of discharge summaries. J Am Med Inform Assoc 2005 Jul-Aug;12(4):448-57.

134. Meystre S, Haug PJ. Natural language processing to extract medical problems from electronic clinical documents: performance evaluation. J Biomed Inform 2006 Dec;39(6):589-99.

135. Zeng QT, Goryachev S, Weiss S, Sordo M, Murphy SN, Lazarus R. Extracting principal diagnosis, co-morbidity and smoking status for asthma research: evaluation of a natural language processing system. BMC Med Inform Decis Mak 2006;6:30.

136. Kuperman GJ, Gibson RF. Computer physician order entry: benefits, costs, and issues. Ann Intern Med 2003;139(1):31-9.

137. Koppel R, Metlay JP, Cohen A, Abaluck B, Localio AR, Kimmel SE, et al. Role of computerized physician order entry systems in facilitating medication errors. JAMA 2005 Mar 9;293(10):1197-203.

138. Ali NA, Mekhjian HS, Kuehn PL, Bentley TD, Kumar R, Ferketich AK, et al. Specificity of computerized physician order entry has a significant effect on the efficiency of workflow for critically ill patients. Crit Care Med 2005 Jan; 33(1):110-4.

\section{Correspondence to:}

Priv.-Doz. Dr. Petra Knaup-Gregori

Department of Medical Informatics

University of Heidelberg

Im Neuenheimer Feld 400

D-69120 Heidelberg

Germany

Tel: +496221567398

E-mail: petra.knaup@med.uni-heidelberg.de 